\title{
Exploring the Interplay of Free Extensive Voluntary ESL Reading with Intensive Reading of Arabic Native Speakers
}

\author{
Negmeldin Alsheikh \\ Dr., United Arab Emirates University, United Arab Emirates, nalsheikh@uaeu.ac.ae
}

\section{Maha Omar Alhabbash}

United Arab Emirates University, United Arab Emirates, 201370115@uaeu.ac.ae

Xu Liu

United Arab Emirates University, United Arab Emirates, 201790106@uaeu.ac.ae

Safa Ahmed AlOthali

United Arab Emirates University, United Arab Emirates, 201790170@uaeu.ac.ae

\section{Najah Obaid Al Mohammedi}

United Arab Emirates University, United Arab Emirates, 201370306@uaeu.ac.ae

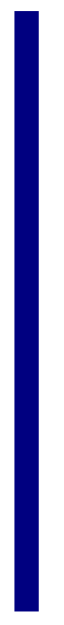

\begin{abstract}
The posing of Intensive Reading (IR) as a fundamental rudimentary reading act and the endorsement of Extensive Reading (ER) as supplemental reading practice seems to be essential for literacy educators. This study tried to unearth the nature of the interplay between intensive and extensive reading as experienced by graduate Arabic native speakers in the United Arab Emirates. Moreover, the study aimed at capturing the students' views about the roles of the intensive reading and extensive reading in shaping their reading experiences. The study employed a sequential explanatory mixed method design. The first phase of the study featured a questionnaire that was collected from students $(n=50)$ followed by interviewing students $(n=4)$ in the second phase. The results revealed that graduate students dealt with reading as a discursive act where they gained from the interplay between the (IR) and (ER). The students viewed the relationship between (IR) and (ER) as reciprocal and hence (IR) promoted (ER) and vice versa. Nonetheless, the nature of the overt instruction and the pre-selected materials used by instructors are viewed as obstructive to the natural flow of (ER). The study recommends that (ER) and (IR) should be treated as part of the continuum in literacy process.
\end{abstract}

Keywords: extensive reading, intensive reading, ESL, Arabic native speakers, graduate students

Citation: Alsheikh, N., Alhabbash, M. O., Liu, X., AlOthali, S. A., \& Al Mohammedi, N. O. (2020). Exploring the Interplay of Free Extensive Voluntary ESL Reading with Intensive Reading of Arabic Native Speakers. International Journal of Instruction, 13(4), 295-314. https://doi.org/10.29333/iji.2020.13419a 


\section{INTRODUCTION}

Semiotic theory furnished a deep understanding of the nature of the text as a discursive object, and how the text affects reader whether as an object for pleasure (Plaisir) or a bliss (Jouissance) (Barthes, 2001). According to Barthes (2001), there are two types of texts: Texte lisible (the readerly) which refers to a readable text that does not challenge the reader's position as a subject and Texte scriptable (the writerly) which means a writable text that provides bliss through provoking literary codes and allowing the reader to break out of his or her subject position. Extensive reading is strongly akin to what Barthes (2001) labeled as a writable text. Barthes (2001) emphasizes the importance of creating a motivated atmosphere to let the readers go beyond the text and find the meaning of their real voices from their readings. This idea is similar to Rosenblatt's (1994) reader-response theory which postulated that the reader is an active agent who imparts a real existence to complete and extend the meaning of the text through continuous interpretation. Therefore, "What is proposed, then, is a portrait-but not a psychological portrait; instead, a structural one which offers the reader a discursive site: the site of someone speaking within himself, amorously, confronting the other (the loved object), who does not speak" (Barthes, 1977, p. 3).

As Rosenblatt (2013) alluded in her transactional theory that reading is a process of developing meaning from a combination of a particular reader, at a particular time and context, with a particular text. It is a transaction among the author, the reader, and the text. That's why reading is called by Rosenblatt (2013) as a choosing activity instead of something controlled and preselected by instructors. In reading, readers bring feelings, attitudes, expectations, and a purpose to each text, and this leads to meaning, or evocation. Rosenblatt (2013) identified two stances that the reader may adopt when transaction is occurred namely, the efferent and the aesthetic stances. When the reader adopts the efferent stance, that means he/she transacts with the text to construct information such as what the college students do, and which strongly relates to the idea of intensive reading. While when the reader adopts the aesthetic stance, it means that the transacting with the text is to focus on the lived experiences depicted in the reading text which refers to the idea of extensive reading.

Many nonnative speakers of English who are college students spend a great amount of time and invest a lot of efforts on academic reading for the college courses in English language as a medium of instruction. In so doing, they try hard to gather information in their respective specialization. "I mostly read for academic purposes throughout my bachelor, master and PhD programs based on course requirements." (A first year $\mathrm{PhD}$ student). In these intensive courses, English as second language (ESL) college students are required and encouraged to read extensively; but instructors usually control the selection of the reading materials in topics, types, genres, quantity (Morgado, 2009; Yin, 2015). As the students continue pursuing graduate studies, the amount and levels of difficulty accelerated and augmented as the students moved from their ungraduated courses level to graduate college courses. This shift makes those students to be voracious readers. This same shift makes the students alternates between intensive to extensive reading. 
More often, some researchers found that reading intensively does not pave the way to become a competent or autonomous reader when a student move to a high level of understanding (Macalister, 2008; Tamrackitkun, 2010; Nishizawa, Yoshioka, \& Ichikawa, 2017). Moreover, Beglar et al. (2012) and Ro (2013) indicated that reading extensively comes into play as the students read for pleasure to break the routine of intensive academic reading. In fact, reading for pleasure do not only facilitate students' knowledge and language skills growth, but also motivates students and builds up their confidence through enjoyment and incidental learning. Additionally, other researchers (e.g. Behrman, 2006; Chen, 2015; Stevens \& Bean, 2007) found that extensive reading serve in developing students' critical literacy skills which enable them to recognize the embedded facets of language, scrutinize power relations in reading texts, detect different voices in reading texts and report their own beliefs of the reading materials. In this case students will go beyond the comprehension level (Abushihab, 2008) to be more critical readers and thinkers (Eftekhary \& Kalayeh, 2014; Tang, 2016). This indicates that the essence of the reading skill as a meaning-focused input serves in creating meaning makers instead of passive readers (Nation; 2007).

Reading as a powerful tool (Krashen, 1993) fuels students' imagination. There are two crucial types of reading that empower second language learning, Intensive Reading (henceforth, IR) and Extensive Reading (henceforth, ER). IR is a teacher-centered reading instruction whereby students are exposed to assigned reading materials to gain detailed information and to be familiar with the writing mechanism of the target language, in this case, students increase their language knowledge and reading strategies under instructors' guidance and assistance. The premise of the IR is that the students' language ability will be enhanced by the acquisition of new knowledge of vocabulary and grammar. In a very important sense, ER leads habitually to Free Voluntary Reading (FVR) as alluded by Krashen (1993) which is a student-centered reading instruction. In FVR, students develop their own reading habits and create for themselves literacy events and practices independently by exposing to a great deal of the reading materials. FVR is based on the assumption that "learn to read by reading" (Krashen, 1993). It enables students' language ability to develop by reading a large amount of meaningful, authentic and interesting materials (Day, 2004; Grabe, 2009). By reading extensively, students develop good reading habits, build up knowledge of the target language, and gain encouragement and pleasure from reading (Krashen, 1993) However, in both kinds of reading, quality and quantity play a crucial role in developing students. For example, Tampubolon and Kusuma (2017) indicated that the quality space of the reading materials provided for students affect their affective responses to the reading texts and their motivation. Reading materials, in this sense, fuel students' imagination and motivate learners to read more.

For the past 20 years, ER has been proved to be an effective instructional means which has significant effect on English vocabulary acquisition, speaking, grammar, writing and motivation. For example, Mason \& Krashen (1997), Biemiller (2005), Sakurai (2017) and Suk, (2017) found that there were real gains in EFL students' reading and writing speed and reading comprehension when using ER. Whereas, Cha (2009), Chang (2015) and Suk, (2017) revealed that ER served in nurturing vocabulary learning rate for 
students, particularly the incidental vocabulary learning as also signified by (Alavi \& Keyvanshekouh, 2012; Alahirsh, 2014). Moreover, Rashtchi \& Pourmand (2014) stressed that beside the significant impact of ER on vocabulary knowledge, it could also increase the level of motivation for readers. Additionally, in a comparative study of ER and IR, Al-Homoud \& Schmitt (2009) found that gaining scores in reading comprehension, reading speed and vocabulary acquisition support that extensive reading approach was just as effective as intensive reading approach. However, the students showed more positive attitudes toward ER over IR in the study. In terms of reading processing capabilities, Rezaee \& Nourzadeh (2011) found that the use of ER maximized the students' bottom up and top down processing capabilities. More recent studies questioned the feasibility and effectiveness of the Free Voluntary Reading (FVR) as compared to the IR. For example, Khoonamri \& Roostae (2014) argued that students in ER without teachers' guidance are prone to be aimless and meaningless readers. Additionally, Macalister (2010) found that college instructors in New Zealand believe that ER enhanced the students' language learning and lead them to read for pleasure, but due to time constrains, ER couldn't be sustained in their curriculum. Furthermore, another comparative study of IR and ER by Rashidi \& Piran (2011) revealed that ER and IR have limited different effect on students' language proficiency; whereas, Claridge (2012) found that college students in New Zealand did not favor ER which was unlikely to develop their language proficiency and knowledge because students need an efferent stance rather than aesthetic stance. Similarly, Can and Baştürk (2016) reported that students were demotivated by ER materials which they read for their courses because they became parts of academic requirements. Other studies conducted by Chiang (2015) and Bahmani and Farvardin (2017) concluded that difficult content reading texts might hamper readers' comprehension abilities and increase their anxiety levels. Moreover, Mikami (2017) implied that students' attitudes and motivation are revealed contradictory results of positive and negative attitudes based on the quality and the quantity of the reading they are exposed to.

In essence, as revealed by many studies (Brumfit, 1997; Anderson, 1999; Nuttall, 2006; Harmer, 2007; Mart, 2015); intensive and extensive readings are commensurate and complementary literacy practices. Moreover, other researchers (e.g. Rashidi \& Piran, 2011; Erfanpour, 2013; Al-Mansour \& Al-Shorm, 2014; Khonamri \& Roostaee, 2014) found that the integration of IR and ER is vital in EFL/ESL context because both IR and ER have pedagogical values and helps in ameliorating reading competency. For example, Rashidi and Piran (2011) indicated that the integration of ER and IR enabled Iranian students to be more proficient and autonomous learners. Moreover, Al- Mansour and Al-Shorm (2014) found that extensive reading program involved intensive instruction, enhanced Saudi students' confidence and provided an optimal learning environment, whereas Khonamri \& Roostaee (2014) stressed that this integration results in tangible gains in students' lexical collocation knowledge.

Given the advantage of high literacy level in reading academic English at the graduate level, it is suggested that curriculum developers should consider the role of the intensive and extensive reading continuum in higher education (Macalister, 2008; Rashidi \& Piran, 2011; Mart, 2012; Erfanpour, 2013). Although, the interplay between intensive 
and extensive reading has received little attention in reading research, where there is not a single study that dealt with the intermingling and the interplay between ER and IR. Specifically, at advanced graduate college students who use high and challenging reading materials. A close look at this interplay between ER and IR may contribute to our understanding of the trajectories of intensive and extensive reading at the graduate students' level. Moreover, the intricacies between ER and IR interplay is not deeply researched especially by advanced graduate students who try to nurture their interest and transform their reading habits to become more autonomous readers. Based on that, the study is guided by the following research objectives: (i) to investigate Arab graduate students' self-report about their intensive and extensive experiences with regard to language skills, reading proficiency, reading opportunity gains and challenges; (ii) to capture the graduate students' views about the roles of their intensive reading and extensive reading as a pathway to extensive reading; (iii) to investigate the nature of the interplay between ER and IR in shaping the experience of advanced readers.

Therefore, the following questions were addressed in this article: (i) What do graduate students' report about their intensive and extensive reading experiences with regard to their language skills, reading proficiency, the opportunity gains and challenges? (ii) How do graduate students view the role of their intensive reading as a pathway to extensive reading? (iii) In what ways does the interplay between intensive and extensive reading add to our understanding of competent and autonomous readers?

\section{METHOD}

This study employed an explanatory sequential mixed method design in two consecutive phases (quan $\rightarrow$ QUAL). Therefore, two major instruments were used in this study; a questionnaire and a semi-structured interview. The rationale behind using the explanatory sequential design was to support and explain the quantitative data through the consolidation of the findings and thus providing in-depth information and validation of the results (Teddlie \& Tashakkori, 2009). Moreover, the quantitative results were used to guide the selection of the sampling for the qualitative phase (Creswell \& Plano Clark, 2011).

In the first quantitative phase of the study, 50 students were selected randomly from the pool of Arabic native speakers who are doing their Master and $\mathrm{PhD}$ in social science through employing simple random sampling strategy. The sampled students were asked to fill out the questionnaire which was adapted from Shen (2008) to answer the first research question. The content of the questionnaire was revised by a panel of judges to establish the content validity (S-CVI) which found to be $(0.80)$. The students were asked to do a self-rating for the questionnaire items by using a 5-point Likert scale from very low to very high. The self-rating scale dealt with English language skills (reading, writing, listening and speaking), their reading proficiency level, the benefits, opportunities and challenges that they experience before and after joining the graduate programs for almost two years. All the statements of the questionnaire were positive. To check the internal consistency reliability among the questionnaire statements, the use of Cronbach's coefficient alpha (0.93) was suitable as the most common internal consistency approach (Miller, Linn \& Gronlund, 2013). 
The second phase featured an interview protocol to answer the second qualitative question in this study. To that end, four PhD students, who read intensively and extensively were recruited purposively for the interview from the initial pool of the first phase, and the seven stages for interview analysis suggested by Kvale (2007) were followed: Thematizing, designing, conducting, transcribing, analyzing and verifying interviews. Moreover, the interviews were intended to gain understanding of the nature of the interplay of the intensive and extensive reading and the intricacies of this interplay. In the transcribing stage, Jefferson's (1983) transcribing techniques were adopted. The content validity of the interview is established through a panel of judges who revise the content of the interview questions. Moreover, During the interview, the researcher clarified and interpreted the meaning for the participants, and thus the interpretive validity of the data was ensured which was defined by Gay, Mills \& Airasian (2011) as "It refers to the meaning attributed to the behaviors or words of the participants" (p. 392). the reliability of the interview focused on the reliability of the interview knowledge, which is called "objectivity" in the thematic analysis. Kvale (2007) advised that objectivity can be notched by using other raters to check the knowledge gained form the interviews to establish trustworthiness.

The third research question focused exclusively on the consistencies and variations between the quantitative and qualitative results. The qualitative results provided more insights and explanations of how different gains extracted from the quantitative results had been achieved through IR or ER interchangeably. Thus, both validity and reliability of the data are established. Figure 3 shows the nature of the mixed method study design and the mechanism and point of interface that were enacted between the quantitative and qualitative phase. 


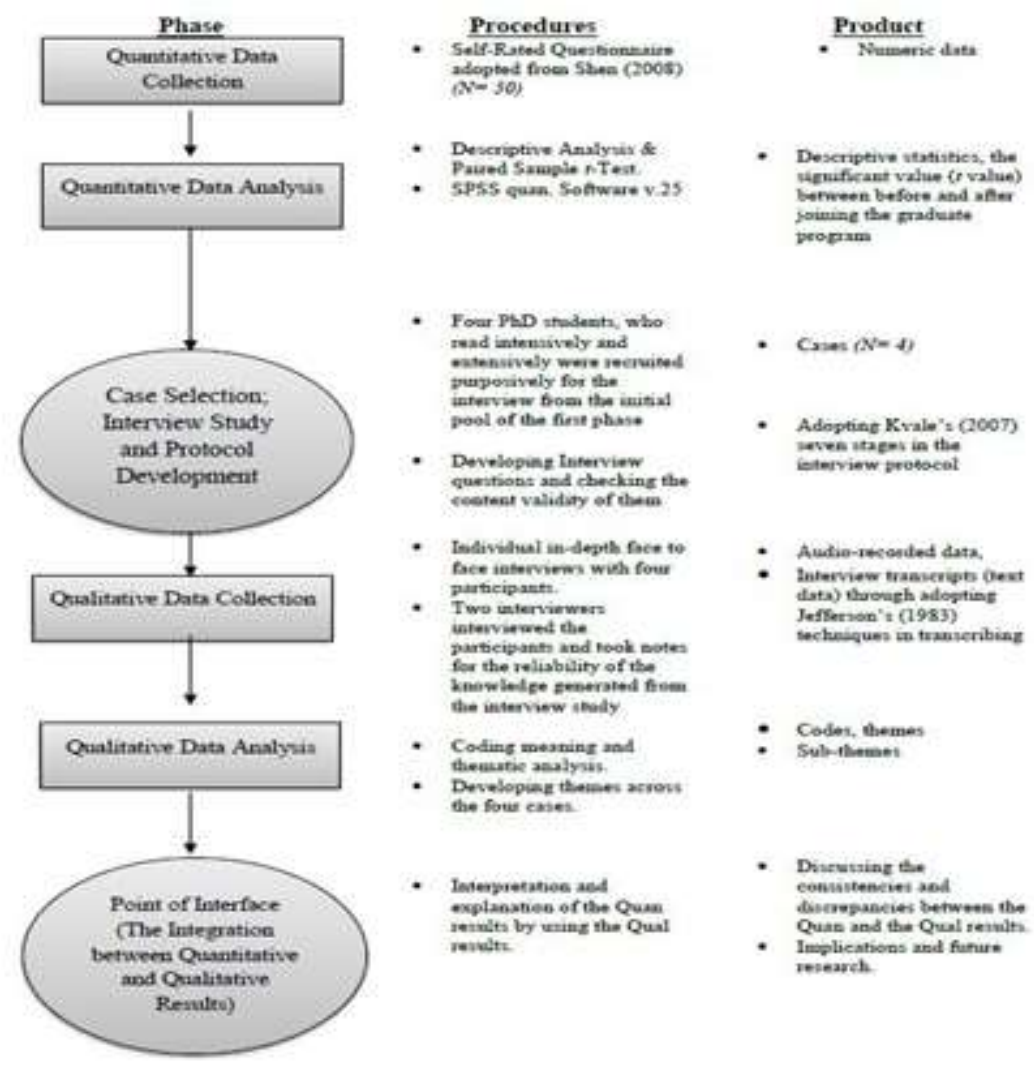

Figure3

A Procedural Diagram for the Explanatory Sequential Mixed Method Design

\section{FINDINGS}

\section{Intensive Reading Leads Them to become Competent Readers}

To answer the first question: What do graduate students' report about their intensive and extensive reading experiences with regard to their language skills, reading proficiency, the opportunity gains and challenges? two paired sample t-tests were run to compare students' language proficiency and reading proficiency before joining the graduate program and after joining the program. The descriptive analysis shows the students' gains in terms of opportunities and benefits as well as challenges that the students encountered after joining the graduate program and reading for an average of six hours per day. 
Table 1 shows the students' self-rating of their English proficiency in terms of listening, reading, writing, and speaking. The result illustrates that there were significant differences between students' Listening Proficiency before joining the program $(M=$ $3.76, S D=.87)$ and after $(M=4.32, S D=.71), t(49)=4.37, p=.000$; between Reading Proficiency level before joining the program $(M=3.92, S D=.80)$ and after $(M=4.42$, $\mathrm{SD}=.57), t(49)=4.48, p=.000$; between Writing Proficiency level before joining the $\operatorname{program}(M=3.54, S D=.99)$ and after $(M=4.3, S D=.68), t(49)=6.35, p=.000$; and between Speaking Proficiency level before joining the program $(M=3.76, S D=.89)$ and $\operatorname{after}(M=4.38, S D=.67), t(49)=5.44, p=.000$.

Table 1

Students' Language Proficiency and Development Comparison $(\mathrm{n}=50)$

\begin{tabular}{lllll}
\hline & & T & df & Sig. (2-tailed) \\
\hline Pair 1 & Listening (before/after) & -4.365 & 49 & .000 \\
Pair 2 & Reading (before/after) & -4.481 & 49 & .000 \\
Pair 3 & Writing (before/after) & -6.348 & 49 & .000 \\
Pair 4 & Speaking (before/after) & -5.444 & 49 & .000 \\
\hline
\end{tabular}

Table 2 shows that students self-rated their reading proficiency in terms of Language Fluency, Critical Reading and Analyses, Comprehension Abilities, Cognitive and Metacognitive Abilities Development, and Critical Communication of Ideas. The result shows that there were significant differences between Language Fluency before joining the program $(M=3.76, S D=.82)$ and $\operatorname{after}(M=4.22, S D=.55), t(49)=4.13, p=.000$; between Critical Reading and Analysis Skills before joining the program $(M=3.48, S D$ $=.93)$ and after $(M=4.32, S D=.59), t(49)=6.52, p=.000$; between Comprehension Abilities before joining the program $(M=.3 .68, S D=.84)$ and after $(M=4.28, S D=$ $.61), t(49)=4.70, p=.000$; between Cognitive and Metacognitive Abilities before joining the program $(M=3.56, S D=.79)$ and after $(M=4.3, S D=.58), t(49)=7.54, p$ $=.000$; between Communicative Abilities before joining the program $(M=3.56, S D=$ $.76)$ and after $(M=4.3, S D=.61), t(49)=7.24, p=.000$.

Table 2

Students' Reading Proficiency and Development Comparison $(\mathrm{n}=50)$

\begin{tabular}{lllll}
\hline & & T & df & Sig. (2-tailed) \\
\hline Pair 1 & Language fluency (before/after) & -4.128 & 49 & .000 \\
Pair 2 & Critical reading and analyses (before/after) & -6.516 & 49 & .000 \\
Pair 3 & Comprehension abilities (before/after) & -4.696 & 49 & .000 \\
Pair 4 & Cognitive and metacognitive abilities & -7.537 & 49 & .000 \\
& development (before/after) & & & \\
Pair 5 & Critical communication of ideas (before/after) & -7.236 & 49 & .000 \\
\hline
\end{tabular}

Figure 1 shows the opportunities and benefits that students have gained after joining the graduate program. The results revealed that the students reported high in the following categories in a descending order: Meaningful Authentic Discussion $(M=4.52)$; Gaining New Concepts, Ideas and Information $(M=4.52)$; Increase of Vocabulary Volume and Fluency $(M=4.48)$; Gaining Confidence in Presenting Ideas $(M=4.42)$; Gaining 
Motivation to Read More $(M=4.26)$ and the least among them which was considered also high is Maximizing Voluntary Reading Involvement $(M=4.1)$.

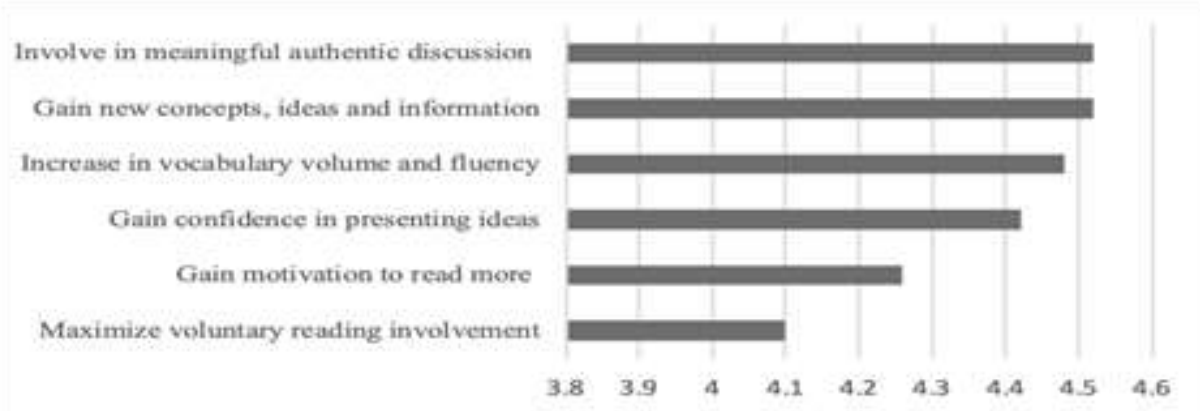

Figure 1

Opportunities and Benefits Gains after Joining the Program

Figure 2 shows the reading challenges that students faced during the program. The illustrated results in 2 indicated that students' report of the challenges they face in ascending order (from least to the most) as follows: Quality of Reading Leads to Demotivation $(M=2.66)$, the Quantity of the Reading Leads to Demotivation $(M=$ 2.86), Difficulty in Reading and Understanding New Concepts $(M=2.98)$, Presenting High Abstract and New Technical Terms $(M=3.00)$, High Cognitive and Metacognitive Abilities Demands $(M=3.00)$, High Readability Level of Materials $(M=3.00)$, and the most challenge reported is More Time Needed to Digest Reading Contents $(M=3.12)$.

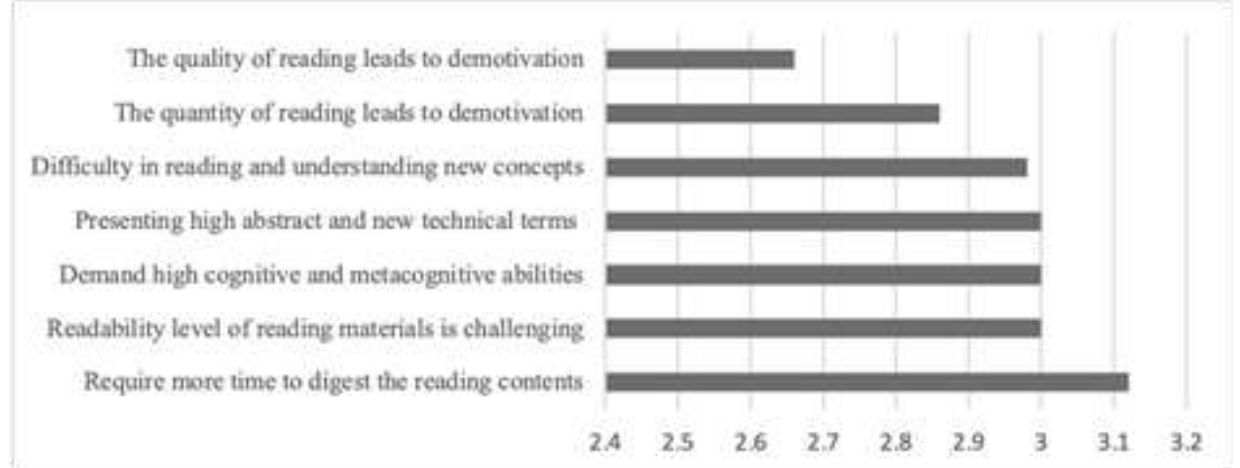

Figure 2

Reading Challenges after Joining the Graduate Program

Overall, the quantitative results revealed that the interplay between the quality and the quantity of the reading materials that graduate students exposed to contributed to a tangible gain in students' language skills, Critical Reading and Analyses, Comprehension, Cognitive and Metacognitive Abilities, and Critical Communication of Ideas. Moreover, the quantity of the reading materials, the quality of the selected reading materials and the use of pedagogical strategies and techniques contributed immensely to comprehensive input experience. This gives an initial indication of how 
the nature of the interplay between the intensive reading and the extensive reading could work within a viable continuum that makes tangible gain in reading experiences.

\section{Students View the Role of Their Intensive as a Pathway to Extensive Reading}

To answer the second question of the study, which is how do graduate students view the role of their intensive reading as a pathway to extensive reading? A semi-structured interview was conducted with four PhD students who experience both ER and IR during their graduate study. Based on the interview analysis, four major themes were extracted from the graduate students' responses, in which each major theme has its own subthemes.

Theme \#1: Intermingling, Continuum, Reciprocity of IR and ER. An immediate occurring theme from the interview data revealed the nature of the interplay between the IR and ER as intermingling, continuum, and reciprocal. In some cases, the IR may stifle the development of the ER. While in other cases IR may enhance ER. The intermingling and reciprocity between IR and ER have existed in three phases based on the participants' responses represented in three sub-themes as follows: 1.1.) IR stands in the way of ER fluidity: Providing graduate students with intensive reading that targets academic reading materials may impede the shift from intensive to extensive reading through a controlled selection from the instructors. This reflected in one of the PhD students' responses represented in example (1). 1.2.) ER feeds and promotes IR: As provided in example (2), a $\mathrm{PhD}$ student started as an extensive reader through reading more and more about different ideas to find her area of interest. Once she started her research, her instructor guided her to narrow her focus on her research topic and to read intensively for that purpose. 1.3.) Dwelling in and find joy in IR when it has relevancy to field: The dominant reading practice of intensive reading shape the graduate students' habits of reading. However, students enjoy intensive reading when it is relevant to their specialization, the relevancy of the materials could pave the way to extensive as viewed in example (3).

It does trigger me to read more for the purpose of understanding about the academic topics... uh... but still I don't see it as leading to more extensive reading.

When I started the program, I started as AN EXTENSIVE READER (.) uh (.) however, from the feedback received from my instructors, they said that I need to be more intensive and focused on my research area... uh

I became more of extensive reader. So, I can't deny the role of my academic intensive reading; however, for me I succeeded to shift to be more extensive.

Theme \#2: The shifting from IR to ER is not without turbulences. From the graduate students' perspectives, the shift from intensive reading to extensive reading is not a smooth process. The students need reading competencies, such as fluency, linguistics competence, effective reading strategies to fathom high quality reading materials. Different turbulences existed from the interview data that demonstrates the transition from IR to ER is not without problems and they are reflected in the following subthemes: 2.1.) High language readability level raises students' comprehension anxiety: If the language used in the selective IR texts is technical and abstract and beyond the 
students' readability level, this may impede the comprehension ability. In example (4) a $\mathrm{PhD}$ student used to consult a dictionary because of the high technical language and new terminologies found in textbooks. 2.2.) Time constraints for shift from IR to ER: Most of the students (see example 5) believe that the amount of readings cannot be covered in one semester even if the reading materials are interesting. 2.3.) Instructor- controlled selection demotivates students: The controlled-selection of the materials by the instructors would not give students the freedom to select what they want to read, which is a crucial feature in extensive reading. These factors sometimes demotivate them because they don't satisfy their interest and needs as readers, which is reflected in their responses in example (6). 2.4.) Instructors' teaching styles stifle learning: The instructors' teaching style also affects and shapes the students' reading habits whether to be more intensive or extensive (See example 7). 2.5.) The quantity and the quality of reading materials kills the joy of reading: Sometimes the quantity of the reading given to the students to read within a limited time might demotivate them and kill their joy for reading. This is manifested in one of the $\mathrm{PhD}$ students' words in example (8) where he expressed that the quantity and quality of reading materials in different courses slows his pace of reading to concentrate and understand in-depth.

(4) For PhD, the type of reading required a dictionary to be beside you because the level of language used is high. In the PhD program the word choice and what the level of the reading is (.) is much higher that sometimes makes my mind congealed and made me anxious. I can't find the time to read the books that I'm interested in (.) which makes me sometimes frustrated because I miss the leisure time that I had before to read what I want to read and to know what I want to know.

I can't say that $100 \%$ of the materials motivate me to read more because (.) some of the assigned materials from the instructor where we don't have the freedom to select the materials we wish to read.

The issue here is that (.) I don't like my instructors' teaching styles. Even

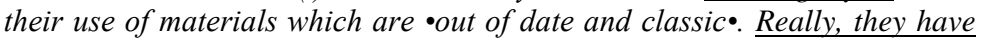
to understand that we are coming from different generation (.) So (.) it depends on the way of teaching these kinds of materials.

Wallah (frankly speaking) I felt depressed even though I enjoy reading but the amount of reading killed me and with the number of courses per semester it was suffocating. What was hard more than the amount of reading is the mental shift from one domain to the other.

Theme \#3: IR promotes positively ER. The positive influence of IR on ER can be captured in different areas that serve in closing the loop between the IR and ER in a very constructive and effective way. These areas were viewed positively by the graduate students based on their reading materials experiences and are represented in four subthemes. 3.1) IR influences positively language fluency and reading confidence: The Students (see example 9) reiterated that IR promoted positively their reading fluency and they became more confident. 3.2.) High IR input indirectly promotes critical thinking: The reading opportunities that the students exposed to during their reading materials ameliorated and sharpened their critical, analytical, evaluation and synthesis 
abilities in reading (see example 10); 3.3.) IR promotes reflective and pragmatic thinking: Most of the students' viewed that their reflective and pragmatic thinking abilities were augmented. They started to mitigate the overt instruction with their situated literacy via a more comprehensive critical scope. In example (11), one of the master students was trying to approach reading the texts in a pragmatic and authentic way through reflecting on her own experiences. 3.4.) IR promotes students' FVR sophisticated choices: The students' exposure to intensive reading calibrated them to refine their reading selections. As in example (12) where One of the PhD students saw herself as becoming more capable to evaluate, choose and select books that resonate with her purpose for reading.

(9) It gave me the confidence to (.)to talk about issues which actually I was hesitant about them before.

I feel I can read much faster than before and I can finish one or two chapters a day through using different reading strategies.

(10) Some professors assigned us some reading papers (.) and I as a PhD student is the one who has to find the link among these article papers, synthesize, criticize and analyse the ideas included in the papers (.)Then I can come and discuss my ideas with them.

(11) I think my cognitive and metacognitive skills are developed (.) because we did a lot of reflective assignments, which gave me the opportunity to think beyond the reading texts (.) uh, actually, (.) now I'm trying to link the reading materials with my experiences and real-life situations. It enhances my thinking and makes me see the ideas with more ENLIGHTENED EYE.

I have now more choices to read in general (.) I can select the book that I want to read carefully and based on my level (.) I even can evaluate the content of the book through a quick scanning if it is useful or not for me.

Theme \#4: IR Overt instruction hampered ER. Some students viewed the IR influence on ER negatively. Two main sub-themes emerged from students' reading experience. 4.1.) IR freezes the FVR flourishment: Students' viewed themselves as still fixated in IR, and that their views don't change albeit their involvement on reading materials for different purposes, see example (13). 4.2.) Reading unrelated materials impact text joy: Sometimes assigning reading to students that does not resonate with their interest may extinct their joy and pleasure for reading as indicated in example (14).

(13) I think that still in the PhD (.) I still consider myself as an intensive reader, because I'm reading what is assigned to me as course requirements, in which I need to read specific chapters and come to lecture to discuss.

Honestly speaking, I hated reading a little because I could not enjoy it and it was initially more of a misery than joy.

\section{DISCUSSION}

In this section, we tried to reconceptualize the interplay between the IR and ER by answering the mixed method question which looked at the consistencies and the variations of the quantitative phase results and the qualitative phase results. Thus, the results will help in recap both the qualitative and quantitative results which is: In what 
ways does the interplay between intensive and extensive reading add to our understanding of competent and autonomous readers?

In this study, the quantitative results revealed that there was a noticeable gain for the graduate students in terms of language skills and reading proficiency. Furthermore, the results also showed that the students' reading opportunities and benefits outweighed the challenges they encountered during their program. In terms of the qualitative results, generally, the students viewed that both types of reading experiences added to them by which they become more competent and autonomous readers. However, the transition between IR and ER as viewed by the students is not without turbulences as the students viewed IR stifles the natural flow of FEVER.

In general, the qualitative results collaborated the quantitative results whereas many facets of consistency exist. First, the quantitative results revealed that the students had made a great gain in their reading skill, followed by speaking, listening and writing. The interview results supported that students viewed their gain in areas of reading fluency, reading strategies, and reflecting on their assigned reading materials. Some students viewed IR had not only impacted their reading fluency but they also felt more confident in using their second language. These results supported Rosenblatt's (2013) views on efferent stance in reading whereas readers transact with the text to construct information and build up their reading fluency that stems from the IR influence.

Second, both qualitative and quantitative revealed compatible results about the nature of reading proficiency. For example, the students self-rated their reading abilities mostly in the area of critical thinking, followed by comprehension, cognitive/metacognitive, and communication skills respectively. This result was manifested through the interview protocol where students viewed that IR made them more critical thinkers. For example, one of the students reflected on how her critical thinking abilities have evolved over time during her graduate studies: "My role as a PhD student is to find the links among these articles, then synthesize, criticize and analyze the ideas included in the papers". Most of the students viewed that their thinking abilities went beyond the assigned textbooks and they have been developed in a way that they became more reflective thinkers and good communicators and disseminators of knowledge and ideas in a compelling and pragmatic way. These students gained benefits from IR as they considered it as a gateway to ER. These results support other studied conducted by Behrman (2006) and Tang (2016) who found that the quality of intensive reading provided for students calibrates and cultivates their critical abilities to comprehend and synthesizes ideas through acquiring major reading skills, strategies, vocabulary, grammatical knowledge and in the ways of tackling ideas in a pensive fashion. Moreover, Eftekhary and Kalayeh (2014) and Chen (2015) assured that the relationship between extensive reading and critical literacy is mutually inclusive and eventually will boost readers' purposeful and incidental learning though IR (Stevens \& Bean, 2007; Abushihab, 2008).

Third, the graduate students gained benefits from their reading experiences in the graduate program. This experiential learning was manifested in the way they participated in real debates and in their acquisition of new concepts, ideas and the 
dissemination of sophisticated theories as they related them to actual practice and personal experiences, they dealt with text nature as a discursive object (Barthes,1977) and as a site of meaning. Moreover, some of the students viewed their extensive reader feeds their ideas and concepts about their area of research interest which they believe become focused and sharpened by reading intensively and with high scope. The nature of the interplay between the IR and ER created a constructive building blocks of knowledge, interest and skills that graduate students need most to match their thinking levels. These findings corroborated many findings from different researchers (Krashen, 1993; Nuttall, 1996; Brumfit 1997; Anderson, 1999; Harmer, 2007; Rashidi \& Piran, 2011; Mart, 2015) who found that there is an evidence of interplay between ER and IR which enhances learners' proficiency and autonomous learning.

Fourth, all the students agreed that there are some challenges they encountered during their reading experiences. The major challenge is that of time constraint, because the students felt more pressured to digest a lot of amount of reading materials in a short period of time. Moreover, the high quality and quantity of reading which teems with sophisticated concepts and ideas, posed another challenge for the students. To that end, the students felt more anxious to communicate their ideas. As one of them puts it: "the level of the reading is (.) is much higher, that sometimes it makes my brain congealed and that made me anxious". These results supported some studies (i.e. Eysenck, 1982; Markham \& Darke, 1991) who posited that anxiety inhibits reading comprehension and that difficult reading content increases readers' anxiety level.

In this study, there are some variations between the qualitative and the quantitative results. For example, the students' self-rating revealed some gains in self confidence in presenting ideas, motivation and Free Extensive Voluntary ESL Reading (FEVER) but these gains as expressed in their views were hampered by instructor-controlled selection of IR and their teaching style. Moreover, the vicarious IR experiences stand in the way of a smooth transition from IR to ER. This finding is similar to Claridge (2012) and Can \& Baştürk (2016) who found that academic reading materials can impact students' motivation in a negative way. Moreover, the students reported that the quality and quantity of reading as the least challenge but in their actual words they viewed them as an actual challenge, and hence it effects the shift from IR to ER. Similar result is found by some researchers (e.g. Krashen, 1982, 1987; Eskey \& Grabe, 1988; Tampubolon \& Kusuma, 2017) who found that the quality and quantity of reading materials have a negative impact on the affective factors of reading which in turn inhibits the IR and ER interplay.

\section{CONCLUSION AND LIMITATION}

The results of this study revealed that there is a continuum, commensurability, and reciprocity between IR and ER and it is difficult to trace their intermingling at different stages of the interplay. But it suffices to say that the graduate students' attitude towards IR and ER can be recapped in major factors such as: reading purposes, interests, instruction, readability level, and reading materials selection. However, these results should be interpreted within the scope and sequence of this study. First, the participants represent a homogenous group of EFL/ESL Arabic native speakers who share the same 
language, culture and specialization. Therefore, the results shouldn't be generalized to other cultural or language group.

\section{RECOMMENDATIONS}

Based on the results extracted from this study, some recommendations should be considered for future research as follows:

1. Future research should consider involving students from different linguistic, cultural and academic backgrounds.

2. Additionally, a longitudinal multiphase mixed method design should be considered in the future to fathom different realities of IR and ER. Thus, different instruments and measurement tools can be used such as document analysis, video-recording, narrative and artifacts.

Furthermore, future research should take instructors' views into consideration.

\section{REFERENCES}

Abushihab, I. (2008). Taking reading beyond comprehension level by developing critical thinking in classroom. Ekev Academic Review, 12(37), 373-384.

Alahirsh, H. (2014). Exploring the effectiveness of extensive reading on incidental vocabulary acquisition by EFL learners: An experimental case study in a Libyan University (Unpublished doctoral dissertation). Nottingham: University of Nottingham.

Alavi, S., \& Keyvanshekouh, A. (2012). Using the Moodle reader as an extensive reading tool and its effect on Iranian EFL students' incidental vocabulary learning. English Language Teaching, 5(6), 135-145.

Al-Homoud, F. A., \& Alsalloum, M. S. (2012). The effects of extensive reading on the breadth and depth of vocabulary knowledge and reading speed. In Proceedings of First Extensive Reading World Congress, 65-67.

Al-Homoud, F., \& Schmitt, N. (2009). Extensive reading in a challenging environment: A comparison of extensive and intensive reading approaches in Saudi Arabia. Language Teaching Research, 13(4), 383-401.

Al-Mansour, N. S., \& Al-Shorm, R. A. (2014). The effect of an extensive reading program on the writing performance of Saudi EFL university students. International Journal of Linguistics, 6(2), 258-275.

Anderson, N. J. (1999). Exploring second language reading: Issues and strategies. Boston: Heine.

Bahmani, R., \& Farvardin, M. T. (2017). Effects of different text difficulty levels on EFL learners' foreign language reading anxiety and reading comprehension. Reading in a Foreign Language, 29(2), 185-202.

Barthes, R. (2001). A lover's discourse: Fragments. (R. Howard, Trans.) New York: Hill and Wang (Original work published 1977). 
Beglar, D., Hunt, A., \& Kite, Y. (2012). The effect of pleasure reading on Japanese university EFL learners' reading rates. Language Learning, 62(3), 665-703.

Behrman, E. H. (2006). Teaching about language, power, and test: A review of classroom practices that support critical literacy. Journal of Adolescent \& Adult Literacy, 49(6), 490-498.

Biemiller, A. (2005). Vocabulary development and instruction: A prerequisite for school learning. In S. Neuman, \& D. Dickinson, The handbook of early literacy research (Vol. 2) (pp.41-51). New York: Guilford.

Brumfit, C. J. (1997). The teaching of advanced reading skills in foreign languages, with particular references to English as a foreign language. Language Teaching, 10(2), 7384.

Can, D. T., \& Baştürk, M. (2016). Affective or cognitive factors on extensive reading of ELT students: A case study. International Journal of Language Academy, 4(1), 206226.

Carrell, P. L., \& Carson, J. G. (1997). Extensive and intensive reading in an EAP setting. English for Specific Purposes, 16(1), 47-60.

Cha, J.-E. (2009). The effects of extensive reading on enhancing vocational high school students' L2 vocabulary \& reading rates. English Teaching, 64(3), 3-30.

Chang, A. C.-S. (2015). An investigation of different text levels on L2 learners' vocabulary learning rates in an extensive reading program. Vocabulary Learning and Instruction, 4(1), 47-57.

Chen, Y. (2015). Creating space for critical literacy in extensive reading class: A practitioner's account. US-China Foreign Language, 13(5), 379-384.

Chiang, M. (2015). Effects of varying text difficulty levels on second language (L2) reading attitudes and reading comprehension. Journal of Research in Reading, 39(4), 121. doi:10.1111/1467-9817.12049.

Claridge, G. (2012). Extensive reading is good for you: Why don't L2 readers of English do more of it? 2012 ACTA International Conference 'TESOL as a Global Trade: Ethics, Equity and Ecology', Retrieved from: http://www.tesol.org.au/files/files/258_gillian_claridge.pdf.

Creswell, J. W. (2013). Qualitative inquiry research design. Thousand Oaks: SAGE.

Creswell, J. W., \& Plano Clark, V. L. (2011). Designing and conducting mixed methods research. London: SAGE.

Day, R. R. (2004). Extensive reading activities for teaching language. New York: Cambridge University Press. 
Eftekhary, A. A., \& Kalayeh, K. B. (2014). The relationship between critical thinking and extensive reading on Iranian Intermediate EFL learners. Journal of Novel Applied Sciences, 3(6), 623-628.

Erfanpour, M. A. (2013). The effect of intensive and extensive reading strategies on reading comprehension: A case of Iranian high school students. English for Specific Purposes World, 14(41), 1-21.

Eskey, D., \& Grabe, W. (1988). Interactive models for second language reading: Perspectives on instruction. In P. L. Carrell, J. Devine, \& D. E. Eskey (Eds.), Interactive approaches to second language reading (pp.223-238). New York: Cambridge University Press.

Eysenck, M. W. (1982). Attention and arousal: Cognition and performance. Berlin: Springer-Verlag.

Gay, L., Mills, G., \& Airasian, P. (2011). Educational research: Competencies for analysis and applications. Boston, USA: Pearson Education.

Grabe, W. (2009). Reading in a second language: Moving from theory to practice. New York: Cambridge University Press.

Hafiz, F., \& Tudor, I. (1989). Extensive reading and the development of language skills. ELT Journal, 43(1), 4-13.

Harmer, J. (2007). The practice of English language teaching. London: Pearson Longman ELT.

Jefferson, G. (1983). Issues in the transcription of naturally-occurring talk: Caricature versus capturing pronunciation particulars. Tilburg Papers on language and Literature. Tilburg: University of Tilburg.

Khonamri, F., \& Roostaee, S. (2014). The impact of tasked-based extensive reading on lexical collocation knowledge of intermediate EFL learners. Social and Behavioral Sciences, 136, 265-270.

Krashen, S. D. (1982). Principles and practice in second language acquisition. New York: Prentice-Hall.

Krashen, S. D. (1987). Principles and practice in second language acquisition. Englewood Cliffs: Prentice-Hall.

Krashen, S. D. (1993). The power of reading: The insights from the research. Englewood: Libraries Unlimited.

Kvale, S. (2007). Doing interviews. New York: SAGE.

Macalister, J. (2008). Implementing extensive reading in an EAP programme. ELT Journal, 62(4), 248-256.

Macalister, J. (2010). Investigating teacher attitudes to extensive reading practices in higher education: Why isn't every doing it? RELC Journal, 41(1), 59-75. 
Markham, R., \& Darke, S. (1991). The effects of anxiety on verbal and spatial task performance. Australian Journal of Psychology, 43(2), 107-111.

Mart, C. T. (2012). Developing speaking skills through reading. International Journal of English Linguistics, 2(6), 91-96.

Mart, C. T. (2015). Combining extensive and intensive reading to reinforce language learning. Journal of Educational and Instructional Studies in the World, 5(4), 85-90.

Mason, B., \& Krashen, S. D. (1997). Extensive reading in English as a foreign language. System, 25(1), 91-102.

Mikami, A. (2017). Students' attitudes toward extensive reading in the Japanese EFL context. TESOL Journal, 8(2), 471-488.

Miller, M., Linn, R., \& Gronlund, N. (2013). Measurement and assessment in teaching. Boston, United States: Pearson.

Morgado, N. F. (2009). Extensive reading: Students' performance and perception. The Reading Matrix, 9(1), 31-43.

Nation, P. (2007). The four strands. Innovation in Language Learning and Teaching, l(1), 2-13.

Nishizawa, H., Yoshioka, T., \& Ichikawa, Y. (2017). Effect of a six-year long extensive reading program for reluctant learners of English. Modern Journal of Language Teaching Methods, 7(8), 116-123.

Nuttall, C. E. (2006). Teaching reading skills in a foreign language. London: MacMillan.

Rashidi, N., \& Piran, M. (2011). The effect of extensive and intensive reading on Iranian EFL learners' vocabulary size and depth. Journal of Language Teaching and Research, 2(2), 471-482.

Rashtchi, M., \& Pourmand, S. (2014). Controlled extensive reading and vocabulary knowledge: Let's move towards autonomous learning in EFL contexts. International Journal of English and Education, 3(2), 132-146.

Renandya, W. A., \& Jacobs, G. M. (2002). Extensive reading: Why aren't we all doing it? In J. C. Richards, \& W. A. Renandya (Eds.), Methodology in language teaching: An anthology of current practice (pp. 295-302). New York: Cambridge University Press.

Renandya, W. A., Sundara Rajan, B. R., \& Jacobs, G. M. (1999). Extensive reading with adult learners of English as a second language. RELC Journal, 30(1), 39-60.

Rezaee, A. A., \& Nourzadeh, S. (2011). Does extensive reading improve EFL learners' processing ability? Theory and Practice in Language Studies, 1(9), 1167-1175.

Ro, E. (2013). A case study of extensive reading with an unmotivated L2 reader. Reading in a Foreign Language, 25(2), 213-233. 
Rosenblatt, L. M. (1994). The reader, the text, the poem: The transactional theory of the literary work. Carbondale: Southern Illinois University Press (Original work published 1978).

Rosenblatt, L. M. (2013). The transactional theory of reading and writing. In D. E. Alvermann, N. J. Unrau, \& R. B. Ruddell (Eds.), Theoretical models and processes of reading (pp. 698-718). Newark, DE: International Reading Association.

Sakurai, N. (2017). The relationship between the amount of extensive reading and the writing performance. The Reading Matrix, 17(2), 142-164.

Shen, M.-y. (2008). EFL learners' responses to extensive reading: Survey and pedagogical applications. The Reading Matrix, 8(2), 111-123.

Stevens, L. P., \& Bean, T. (2007). Critical literacy: Context, research, and practice in the $K-12$ classroom. Thousand Oaks: SAGE.

Suk, N. (2017). The effects of extensive reading on reading comprehension, reading rate, and vocabulary acquisition. Reading Research Quarterly, 52(1), 73-89.

Tampubolon, A. C., \& Kusuma, H. E. (2017). Effects of reading motivation and perceived quality of the reading space on students' affective responses. Journal of Asian Architecture and Building Engineering, 16(3), 559-563.

Tamrackitkun, K. (2010). Extensive reading: An empirical study of its effects on EFL Thai students' reading comprehension, reading fluency and attitudes (Unpublished doctoral dissertation). University of Salford, Salford.

Tang, L. (2016). Exploration on cultivation of critical thinking in college intensive reading course. English Language Teaching, 9(3), 18-23.

Teddlie, C., \& Tashakkori, A. (2009). Foundations of mixed methods research: Integrating quantitative and qualitative approaches in the social and behavioral sciences. New York: SAGE.

Yin, L. (2015). The problems and solutions in intensive reading course teaching. International Conference on Economics, Social Science, Arts, Education and Management Engineering (pp. 143-147). Xi'an: Atlantis Press. 


\section{Appendix A}

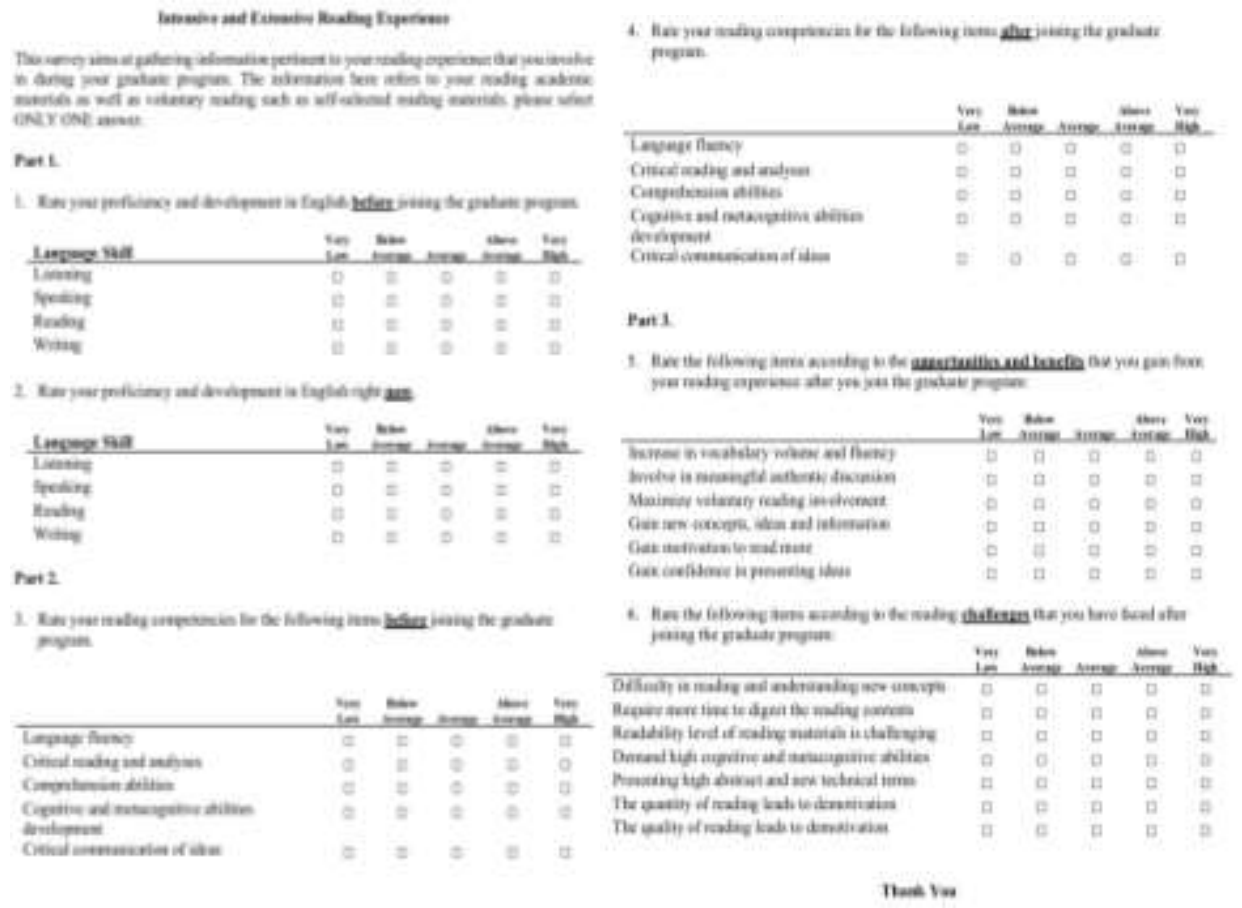

\section{Appendix B}

Jefferson's Techniques in Transcribing Conversations

\begin{tabular}{|c|l|}
\hline$>$ Text $<$ & It refers that the produced speech is faster than the normal one. \\
\hline$(\mathbf{1})$ & It symbolizes the pauses in seconds \\
\hline$(\mathbf{.})$ & It represents quick and untimed pause. \\
\hline ((Text)) & It includes comments was written by the researcher about people's body language \\
\hline[ & The left square refers to the interruption of the speech \\
\hline [ & The right square indicates the end of the overlap or interruption \\
\hline = & It represents a sudden end in the middle of the word \\
\hline Text & It indicates quick turn taking in the conversation. \\
\hline TEXT & It indicates that the speech is quieter than the others surrounding it. \\
\hline Text & It indicates that the speech is louder than the others surrounding it. \\
\hline
\end{tabular}

